\title{
A systematic review of malignancy-associated hemophagocytic Iymphohistiocytosis that needs more attentions
}

\author{
Hongluan Wang ${ }^{1,2,3, *}$, Lixia Xiong ${ }^{1,2, *}$, Weiping Tang ${ }^{1,2}$, Ying Zhou ${ }^{2}$ and Fei $\mathbf{L i}^{1}$ \\ ${ }^{1}$ Department of Hematology, The First Affiliated Hospital of Nanchang University, Nanchang, Jiangxi 330006, China \\ ${ }^{2}$ Medical College, Nanchang University, Nanchang, Jiangxi 330006, China \\ ${ }^{3}$ Department of Respiratory, Jiangxi Provincial People's Hospital, Nanchang, Jiangxi 330006, China \\ *These authors contributed equally to this work
}

Correspondence to: Fei Li, email: yx021021@sina.com

Keywords: hemophagocytic lymphohistiocytosis, hemophagocytic syndrome, malignancy, lymphoma

Received: May 17, $2017 \quad$ Accepted: June 29, $2017 \quad$ Published: July 14, 2017

Copyright: Wang et al. This is an open-access article distributed under the terms of the Creative Commons Attribution License 3.0 (CC BY 3.0), which permits unrestricted use, distribution, and reproduction in any medium, provided the original author and source are credited.

\section{ABSTRACT}

As an infrequent but potentially life-threatening hyperinflammatory syndrome, hemophagocytic lymphohistiocytosis (HLH) is clinically characterized with prolonged fever, hepatosplenomegaly, cytopenia, hypertriglyceridemia, hyperferritinemia and hemophagocytosis in bone marrow, liver, spleen or lymph nodes. Malignancyassociated HLH (M-HLH), one type of acquired HLH, usually presents variable overlaps of symptoms with other types of $\mathrm{HLH}$, thus resulting in higher incidence of misdiagnosis and mortality. In recent years, with the increasing awareness to this disease, the diagnosis and management of HLH have gained more and more attention, and improvements have been made accordingly. As a result, the survival of patients is greatly prolonged. However, there is still no consensus on the diagnostic criteria and treatment strategies due to lack of large samples or prospective clinical trials. In order to improve recognition and diagnosis, and provide guidance regarding the treatment of M-HLH, the Study Group in HLH Subtypes of the Histiocyte Society has developed consensus recommendations for the diagnosis and management of M-HLH in 2015. In the present article, we summarized and discussed some updated understandings in M-HLH.

\section{INTRODUCTION}

Hemophagocytic lymphohistiocytosis (HLH), also called hemophagocytic syndrome (HPS), is an infrequent but potentially life-threatening hyperinflammatory syndrome, including impaired function of cytotoxic $\mathrm{T}$ lymphocytes and natural killer (NK) cells, as well as macrophages [1]. The clinical characteristics of HLH are complicated, generally including prolonged fever, hepatosplenomegaly, cytopenia, hypertriglyceridemia, hyperferritinemia and hemophagocytosis in bone marrow, liver, spleen or lymph nodes. Primary HLH consists of several genetic conditions, including familial-HLH (F-HLH) 2-5, Griscelli syndrome type II, Chediak-Higashi syndrome and other types. HLH is mainly triggered by infections, and the onset of primary HLH usually occurs during childhood although reports regarding its adult presentation are increasing [2]. Secondary or acquired HLH is caused by a wide range of causes, including infections, malignancies, autoimmune diseases, metabolic diseases and acquired immune deficiencies (such as AIDS, iatrogenic immune suppression and organ or stem cell transplantation) [3]. In the past 10 years, more than 1,500 publications have appeared with the increasing awareness to this disease [4]. Of these, HLH in the context of malignancy is considered as a big challenge to clinicians due to variable overlaps of symptoms with other types of HLH, sepsis and multiorgan failure, thus resulting in higher incidence of misdiagnosis and mortality [3]. Prompt diagnosis and treatment are crucial to initiate appropriate treatment, which can avoid a fatal outcome caused by multiorgan dysfunction. However, only very few reports currently focus on the malignancy-associated HLH (M-HLH) due to low incidence and insufficient 
knowledge. Therefore, we reviewed some key points, including epidemiological data, predisposing factors, diagnosis, treatment strategies and prognosis of M-HLH in this article, and our study provided the valuable guidance for the treatment of M-HLH patients.

\section{Epidemiological profile}

HLH is a rare disease, but it presents an increasing incidence in recent years. Currently, the accurate epidemiological profile of HLH is not well defined. Some surveys in Italy, Sweden and USA have reported that the estimated annual incidence of HLH is approximately 800,000 people and 1-10 per 1 million children [5-7]. Similarly, the epidemiological data in M-HLH patients also remain limited. In recent years, patients with hematologic neoplasms, especially lymphoma, are prone to HLH, which has gained more and more attention by clinicians. HLH affects $1 \%$ of adults with hematologic tumor, but the incidence is increased to $20 \%$ in some patients with B- and T-cell lymphomas [8]. A large series of studies from 2,197 adult HLH patients have demonstrated that M-HLH accounts for approximately $50 \%$ of adult HLH. The most common tumor types for triggering $\mathrm{HLH}$ are hematological neoplasms (93.7\%) with T- or NK cell lymphoma or leukemia $(35.2 \%)$, followed by B-cell lymphoma $(31.8 \%)$, other nonspecified hematologic neoplasms $(14.4 \%)$, leukemia (6.4\%) and Hodgkin lymphoma (5.8\%). Solid tumors and non-specified neoplasms account for $3.1 \%$ and $3.2 \%$, respectively [9] [Figure 1]. In T-cell malignancies, peripheral T-cell lymphoma, primary cutaneous $\gamma \delta$-Tcell lymphoma, anaplastic large cell lymphoma and lymphoblastic lymphoma are more likely to trigger HLH $[10,11]$. In addition, diffuse large B-cell lymphoma (DLBCL) is the most frequent B-cell lymphoma that can trigger HLH. B-precursor acute lymphoblastic leukemia is sporadically reported, which is the most common childhood tumor [12]. No specific predominant subtype is reported in Hodgkin lymphoma [13]. Other malignant or non-malignant hematologic diseases associated with $\mathrm{HLH}$ include Epstein-Barr virus (EBV)-associated T/ NK-cell lymphoproliferative disorders, leukemia, myelodysplastic syndrome, Langerhans cell histiocytosis, multicentric Castleman disease and cytophagic histiocytic panniculitis [14-17]. Solid tumors, such as Wilms tumor [18] and germ cell tumors [19], are sporadically reported with the incidence of only $3 \%$ in adult HLH patients [9]. Geographical variability is another epidemiological characteristic of HLH patients. DLBCL-triggered HLH is predominant in Western countries and Japan [20, 21], while T-cell neoplasm is the major trigger of HLH in China and Korea $[22,23]$, suggesting that specific genetic backgrounds affect the distribution of cause for HLH patients [10]. Table 1 lists some types of M-HLH.
HLH can be observed at any age, but the probability to develop HLH in patients with lymphoma may increase with the age. A large survey with $799 \mathrm{HLH}$ patients in Japan indicates that lymphoma is detected in $68 \%$ of patients over 60 years old, $38 \%$ of patients within 30-59 years old, $10 \%$ of patients within 15-29 years old, and $0 \%$ of patients under 14 years old [21]. However, another report has shown that M-HLH is observed in pediatric and adolescent patients with the prevalence of approximately 8\% [49]. In addition, Hodgkin lymphoma has been presented in several types of hereditary HLH [50]. Booth et al. have reported that B-cell non-Hodgkin lymphoma (NHL) occurs in $24 \%$ of patients with X-linked lymphoproliferative syndrome type I, a disorder associated with aggressive $\mathrm{HLH}$, due to $S A P / S H 2 D 1 A$ deficiency [51]. Moreover, malignancies have also been reported in patients with F-HLH 2, 4 and 5, who are detected to have hypomorphic alleles in PRF1, STX11 and STXBP2 [52].

\section{Predisposing factors}

Malignant cells or/and infections, such as viruses, invasive fungi and bacteria, are the major triggers or co-triggers contributing to the secretion of excessive cytokines and the development of HLH, such as EBVassociated lymphoma. HLH can occur during the phase of onset or relapsed malignancies, also during the phase of chemotherapy, including induction, consolidation and even maintenance therapy due to therapy-induced immunosuppression, which usually occurs in the treatment of lymphoma or leukemia.

Malignant or infected cells can initiate the immune response. Dysfunctional cytotoxic CD8+ T lymphocytes (CTLs) and NK cells are unable to initiate a proper response against the target cells. This results in an uncontrolled proliferation of the CTLs, a large production of interferon- $\gamma$ (INF- $\gamma$ ) and proliferation of histiocytes (macrophages) that subsequently invade organs, such as liver, spleen and lymph nodes, and produce a further storm of cytokines, including INF- $\gamma$, TNF- $\alpha$, and interleukins (IL)-1, 6 and 18 [5]. The proliferating histiocytes engulf red cells, white cells, platelets and are called hemophagocytes.

More attention should be paid to the correlation among EBV infection, lymphoma and HLH. As one of the herpes groups, EBV infects more than $95 \%$ of the adult population worldwide and is the most frequent infective trigger of HLH. Many types of lymphoma, such as T/NK cell lymphoma, have been identified to be related to EBV infection. Its transmission occurs predominantly through exposure to infected saliva. EBV has a well-described tropism for B cells, and the invasion of CTL and NK cell populations plays an important role in the pathogenesis of HLH. Abnormal cytotoxic activity prevents efficient removal of infected cells, leading to continuous antigenic 
Table 1: Previously reported malignancy-associated HLH

\section{Malignancy-associated HLH}

Malignancy-triggered HLH

T-cell or NK-cell lymphoma

B-cell lymphoma

Hodgkin lymphoma

Not specified lymphoma

Leukemia

Other hematological neoplasms

Solid tumor

Not specified neoplasm

HLH during chemotherapy

\section{Reported cases}

Peripheral T-cell lymphoma (Unspecified) [24]

NK/T cell lymphoma, aggressive NK cell leukemia, gastric T-cell lymphoma

[24]

Anaplastic large cell lymphoma, ALK negative [25]

Anaplastic large cell lymphoma, ALK positive [26]

Angioimmunoblastic T-cell lymphoma [27]

Panniculitis-like T-cell lymphoma [28]

Gamma-delta $(\gamma \delta)$ T-cell lymphoma [29]

Lymphoblastic lymphoma/leukemia, Hepatosplenic T-cell lymphoma [30]

Diffuse large B-cell lymphoma [31]

T-cell/histiocyte-rich large B-cell lymphoma [32]

Follicular lymphoma, marginal zone lymphoma, intravascular large B-cell lymphoma, Burkitt's lymphoma [30]

Lymphocyte-depleted Hodgkin lymphoma [13]

Primary bilateral adrenal lymphoma [33]

Acute lymphoblastic leukemia (B-cell precursor acute lymphoblastic leukemia, T-cell acute lymphoblastic leukemia) $[34,35]$

Acute myelocytic leukemia [36]

Acute monoblastic leukemia [37]

Acute erythroid leukemia [38]

Acute megakaryocytic leukemia [39]

Chronic lymphocytic leukemia [40]

Castleman's disease [41]

Myelodysplastic syndromes [42]

Multiple myeloma [9]

Wilms tumor [18]

Germ cell tumor [19]

Lung cancer, prostate cancer, hepatocellular carcinoma [43]

Colonic malignancy [28]

Squamous cell carcinoma of the neck [44]

Mediastinal endodermal sinus tumor [45]

Acute myeloid leukemia [46]

Acute promyelocytic leukemia [47]

Chronic lymphocytic leukemia [48]

T-cell acute lymphoblastic leukemia [49]

Classical Hodgkin lymphoma [49]

Neuroblastoma [20] stimulation and dysfunctions of CTLs and NK cells and finally resulting in life-threatening hyperinflammatory syndrome and HLH.

\section{Diagnosis and differential diagnosis}

The clinical presentations, signs and laboratorial abnormalities of $\mathrm{HLH}$ are diverse, mainly including continuous high fever $\left(>38.5^{\circ} \mathrm{C}\right)$, hepatosplenomegaly, cytopenia, skin rashes, panniculitis-like cutaneous nodules, multiple involvement of internal organs, increased lactate dehydrogenase (LDH), hypertriglyceridaemia, hyperferritinaemia, disseminated intravascular coagulopathy and high concentrations of soluble CD25 or CD163. The diagnostic criteria for HLH are in accordance with the guideline proposed by the Histiocyte Society in 1991 and updated in 2004. Table 2 lists the diagnostic criteria of HLH2004.

The diagnosis of M-HLH is particularly challenging because the symptoms are nonspecific and many 
Table 2: HLH-2004 diagnostic criteria [53]

- Genetic defect consistent with HLH

- Fulfillment of five of the eight following clinical criteria:

1. Fever

2. Splenomegaly

3. Cytopenia

Hemoglobin

Platelets

Neutrophiles

4. Hyperferritinemia

5. Hypofibrinogenemia or hypertriglyceridemia

6. Elevated soluble CD25

7. Hemophagocytosis

8. Reduced or absent NK cytotoxicity

\section{Supportive evidence}

Elevated transaminases and bilirubin

Elevated lactate dehydrogenase

Elevated d-dimers

Elevated cerebrospinal fluid cells and/or protein
Temperature $>38.5^{\circ} \mathrm{C}$ for $>7$ days

Spleen tip palpated $>3 \mathrm{~cm}$ below left costal margin

$\geq 2$ lineages

$<90 \mathrm{~g} / \mathrm{L}$ (neonates $<100 \mathrm{~g} / \mathrm{L}$ )

$<100 \times 10^{9} / \mathrm{L}$

$<1 \times 10^{9} / \mathrm{L}$

$>500 \mu \mathrm{g} / \mathrm{L}$

$<1.5 \mathrm{~g} / \mathrm{L}$, or $>3 \mathrm{mmol} / \mathrm{L}$

$>2,400 \mathrm{U} / \mathrm{mL}$

Bone marrow, spleen, liver, lymph node or other tissues
NK: natural killer cells.

symptoms overlap among some severe illnesses, including sepsis, systemic inflammatory response syndrome (SIRS), multiorgan failure and hematologic malignancies. So far, there are no universally accepted diagnostic criteria for M-HLH. It still remains controversial whether the widely used HLH-2004 criteria are suitable for M-HLH patients, because the first criteria defined in the 1990s were based on the pediatric patients from the international treatment HLH-94 study and expert opinions modified according to the subsequent HLH-2004 study [53]. Other diagnostic indicators have not gained the wide acceptance. For example, Takahashi et al. [54] have proposed to add

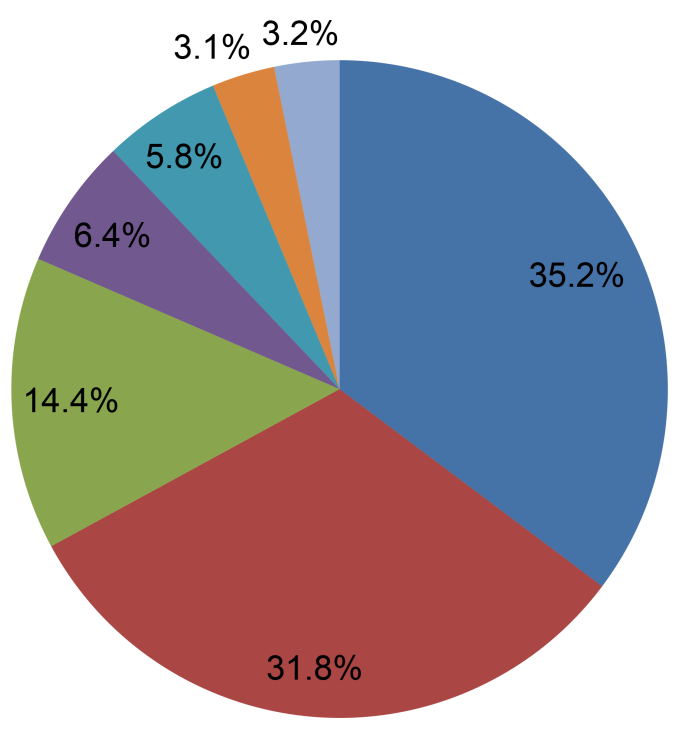

Figure 1: The tumor types of malignancy-associated HLH.
LDH and d-dimers into the diagnostic criteria based on 142 cases with adult lymphoma-associated HPS (LAHS). Maruoka et al. [55] have identified IP-10/CXCL10 and MIG/CXCL9 as novel markers for the diagnosis of LAHS using cytometric bead array (CBA) with sensitivity and specificity of $100 \%$ and $95 \%$, respectively. Furthermore, IP-10 and MIG have been used to distinguish LAHS from sepsis in patients with hematologic malignancies. In addition, EBV is a frequent co-trigger in $24 \%$ of M-HLH patients and in $88 \%$ of patients with HLH during chemotherapy (C-HLH) [49]. In spite of the limitations, the HLH-2004 criteria are still universally accepted as

- T or NK cell lymphoma/leukemia

- B-cell lymphoma

non-specified hematologic neoplasms

- Leukemia

- Hodgkin lymphoma

nolid tumors

- Non-specified neoplasm 
a substitute definition [56]. Patients with five of eight criteria and potential malignancy can be diagnosed as M-HLH.

Lymphoma should be considered as a possible underlying disease in any HLH patients. It is also suitable for patients with obvious EBV, CMV or HIV infection. It is well known that EBV infection as a co-trigger is observed in $90 \%$ of Hodgkin lymphoma and approximately $33 \%$ of peripheral T-cell lymphoma [20, 57]. Lymphoma can be detected in more than $50 \%$ of adult HLH patients with HIV infection [58]. In addition, in patients with immunityassociated HLH, such as systemic lupus erythematosus, systemic juvenile idiopathic arthritis or adult-onset Still's disease (AOSD), a careful search of a malignancy should be recommended to avoid any missing diagnosis of hidden neoplasms. Under some hereditary conditions predisposing to HLH, malignancy, especially lymphoma, should also be excluded.

Previous studies have reported that several indicators reflect the severity of diseases, which can be used to further screen the possible M-HLH patients. Soluble IL-2 receptor (sCD25) is a valuable marker with constantly increased level during active HLH. In addition, a high ratio of CD25 to ferritin is more often detected in LAHS and may be a useful marker to distinguish other types of HLH [59]. Moreover, we have retrospectively analyzed the clinical characteristics, laboratorial findings and survival time in 16 LAHS patients from 69 adult HLH patients, and found that LAHS patients have obviously lower levels of fibrinogen $(\mathrm{Fbg},<1.5 \mathrm{~g} / \mathrm{L})$ and platelet $\left(\mathrm{PLT},<40 \times 10^{9} / \mathrm{L}\right)$, higher levels of $\mathrm{LDH}(\geq 1,000 \mathrm{U} / \mathrm{L})$ and the worst survival compared with other types of HLH [24]. These characteristics may offer more likelihood for us to screen potential lymphoma. As for these suspicious patients, X-ray of the chest and ultrasound or computed tomography of the abdomen should be recommended to screen enlarged lymph nodes. Suspicious lymph nodes or cutaneous lesions should be biopsied. If it is possible, magnetic resonance imaging (MRI) or positron emission tomography (PET) may be helpful for the diagnosis in some cases.

Other severe illnesses, including sepsis, SIRS and multiorgan failure, usually share similar clinical symptoms and laboratorial abnormalities as HLH, making the differentiation more complicated. Moreover, two diagnostic indicators (high concentration of soluble CD25 and decreased NK-cell activity) are also reported in sepsis, SIRS and multiple organ dysfunction syndrome (MODS), suggesting that these diseases may share some common mechanisms [9]. Hyperferritinemia may be a major indicator in the differentiation of HLH from other systemic diseases. Allen et al. [60] have assessed 330 patients with high ferritin levels (greater than $500 \mu \mathrm{g} / \mathrm{L}$ ), and 10 patients are diagnosed as HLH. Ferritin, as an indicator, is $90 \%$ sensitive and $96 \%$ specific for HLH when its level is over $10,000 \mu \mathrm{g} / \mathrm{L}$. However, the elevated ferritin must be differentiated from transfusion-related iron or malignancy-related overload.

\section{Treatment}

The treatment of M-HLH aims to control the overactive immune system and treat malignancy. However, there are no universal conclusions on whether an HLHdirected, malignancy-directed or combined approach should initially be adopted due to lack of prospective, randomized or controlled clinical trials. Therefore, treatment decisions are usually made based on clinical experience, expert's opinions and clinical cases. The major drugs, including glucocorticosteroids, cyclosporine A (CsA) and etoposide (VP16), are usually used to initially treat and rapidly control hyperinflammation and hipercytokine response according to the protocols of HLH-2004. However, as for patients with central nervous system (CNS) involvement, dexamethasone (Dex) is the preferred corticosteroid because it can cross the bloodbrain barrier better than prednisone or prednisolone. Although cyclosporine is the most frequently used immunosuppressive drug in HLH patients associated with autoimmune diseases [9], it remains controversial whether it is suitable for M-HLH patients.

Malignancy-directed and HLH-directed therapies are frequently overlapped. In LAHS patients, an etoposide-based chemotherapy regimen should be strongly considered [61]. Etoposide can inhibit topoisomerase II, thus leading to the breakage of double-stranded DNA. Meanwhile, etoposide can selectively deplete activated $\mathrm{T}$ cells to suppress the production of inflammatory cytokines and improve the survival in a murine model of HLH [62]. A study has reported that the mortality rate is increased by 14 times in children with EBV-associated HLH if etoposide is not provided within the first 4 weeks [63]. Other reports in adult cases have also indicated that regimens containing etoposide are associated with better survival [9]. In circumstances with EBV infection or unknown genetic predisposition, an etoposide-based regimen should be initiated without delay, which targets to immune dysregulation, EBV infection and malignancies.

There are very limited data on the treatment of C-HLH. Whether HLH-directed regimens are optimal for these patients depends on the severity of HLH and the possible triggers. Infections resulted from chemotherapyinduced immunosuppression are major triggers in $\mathrm{C}$-HLH patients. The major triggers include viruses, invasive fungi and bacteria. Therefore, if infections occur in C-HLH patients, postponing chemotherapy or interruption of maintenance therapy should be considered, except for neoplasm relapse. Glucocorticosteroids and immunoglobulins can be administered to HLH patients $[64,65]$. If possible, anti-infectious prophylaxis and powerful anti-infective treatment should be strongly considered in active HLH patients. Whether more 
aggressive treatment, such as etoposide, is beneficial for these patients still remains largely unexplored [65].

Anti-viral treatment should be performed if an obvious viral trigger is found, such as EBV, CMV or adenovirus. It has been reported that rituximabcontaining immunochemotherapy benefits EBV-related HLH or malignancy patients with EBV infection [64]. Usually, rituximab can eliminate EBV-infected B cells, thus effectively playing an anti-virus role. However, EBV ectopically infects $\mathrm{T}$ or NK cells in majority of HLH patients in Asian countries, therefore, a combination of Dex/etoposide (VP16) or CsA controls EBV-infected $\mathrm{T}$ cells or NK cells. Alemtuzumab, an anti-CD52 monoclonal antibody, can also be used in the treatment of EBV-infected T cells or to destroy mature lymphocytes in T-cell lymphoma.

Stem cell transplantation (SCT), including allogeneic SCT, matched unrelated donor SCT and reduced-intensity conditioning (RIC) SCT, has revolutionized the treatment and resulted in long-term survival even cure in part of LAHS patients. However, bone marrow transplantation should be avoided in individuals with active disease because of cytokine storm and increased risk of graft-versus-host disease.

Standard therapy shows an obviously improved survival rate of HLH patients, while approximately $30 \%$ patients unresponsive to standard therapy are called as refractory HLH patients. So far, only few studies have focused on refractory HLH. Patients who do not achieve at least partial response 2 or 3 weeks after initial standard HLH therapy should be classified as refractory HLH $[65,66]$. Effective salvage therapy can control refractory HLH to acquire time and chance for further therapy, thus prolonging the survival of the patients. A multi-center prospective study has analyzed the data from 63 adult HLH patients after DEP regimen (liposomal doxorubicin, etoposide and methylprednisolone) as a salvage treatment, a total of 29 patients are diagnosed as LAHS, and the overall response rate is $75.7 \%$ [66]. In addition, alemtuzumab as salvage therapy has been reported to improve the survival and achieve more time for allogeneic SCT in some refractory HLH patients. In EBV-related HLH patients with or without lymphoma, rituximab can be an option of salvage treatment [67]. Other novel drugs, such as infliximab, daclizumab, anakinra, vincristine and tocilizumab, have been also reported to apply in the refractory HLH patients [68]. Recently, another interesting development has been seen that thalidomide enhances the release of IL-2 and IFN from activated $\mathrm{T}$ cells, inhibits the immunosuppressive activity of regulatory $\mathrm{T}$ cells and increases NK-cell mediated cytotoxicity, thus inhibiting the release of TNF and other cytokines, including IL-6. However, it is still difficult to acquire reliable data from $\mathrm{M}-\mathrm{HLH}$ because these reports are mainly based on case reports or other types of HLH [69].

\section{Prognosis}

HLH is one of the most critical clinical disorders with a mortality rate of approximately $41 \%$ [9]. The survival data from several studies have shown that approximately 56-70\% patients have a median overall survival of 36-230 days, and the 3-year survival of M-HLH patients is $18-55 \%$ [9]. Moreover, T-cell lymphoma-triggered HLH has a worse prognosis than B-cell lymphoma-triggered HLH. In a Japanese study, the 5-year overall survival rate in HLH patients with $\mathrm{T} / \mathrm{NK}$-cell lymphoma is only $12 \%$, while it is $48 \%$ in HLH patients with B-cell lymphoma $[20,22,23,70]$. Prognostic factors associated with mortality include thrombocytopenia, high onset age, possible lymphoma, increased ferritin levels, low Fbg level and EBV-DNA $>1,000$ copies $[17,71]$. Our previous retrospective analysis has indicated that active EBV infection, malignancy, low Fbg, low PLT and high LDH levels can predict high death risk and very poor prognosis $[3,24]$. There are different prognostic factors for M-HLH and C-HLH. Underlying neoplasia or/and EBV infection are major prognostic factors in M-HLH patients, while infections, especially EBV infection and invasive fungal infection, may be the major factors in C-HLH patients. Other predictive factors, such as decreased number of CD3+ cells, have been reported to be adversely associated with survival of HLH patients [70]. Low glycosylated ferritin concentration is a predictive marker of severe HLH [71]. Moreover, bone marrow increased 18F-2-fluoro-2-deoxy-D-glucose (FDG) uptake on $\mathrm{PET} / \mathrm{CT}$ may be a promising predictor for the extent of cytokine storm and the overall survival of LAHS patients [72]. The sensitivity, specificity and diagnostic accuracy of PET/CT for malignancy detection are $83,62.5$ and $71.4 \%$, respectively [30].

\section{CONCLUSIONS}

Taken together, M-HLH is an increasingly recognized but life-threatening disease, which is associated with rapidly deteriorated clinical process and very high mortality. Currently, there is little evidence for M-HLH, especially for the diagnosis and therapeutic approach. With increased understanding of M-HLH, multidisciplinary collaboration is urgently required to promote international multicenter prospective study and develop clinical guidelines, thus finally improving the overall survival of M-HLH patients.

\section{Authors' contributions}

FL, LX and HW designed and wrote the manuscript. WT and YZ contributed to the review and revision of the manuscript. FL contributed to the final review and approval of the manuscript. 


\section{CONFLICTS OF INTEREST}

The authors declare no conflicts of interest.

\section{FUNDING}

This work is financially supported by the grants from the National Natural Science Foundation of China (81560034), the Natural Science Foundation of Jiangxi Province (20142BAB205072) and Young Scientist Training Program (20153BCB23040) of Jiangxi Province.

\section{REFERENCES}

1. Chandrakasan S, Filipovich AH. Hemophagocytic lymphohistiocytosis: advances in pathophysiology, diagnosis, and treatment. J Pediatr. 2013; 163:1253-1259.

2. Zhang K, Jordan MB, Marsh RA, Johnson JA, Kissell D, Meller J, Villanueva J, Risma KA, Wei Q, Klein PS, Filipovich AH. Hypomorphic mutations in PRF1, MUNC13-4, and STXBP2 are associated with adult-onset familial HLH. Blood. 2011; 118:5794-5798.

3. Li F, Yang Y, Jin F, Dehoedt C, Rao J, Zhou Y, Li P, Yang G, Wang M, Zhang R, Yang Y. Clinical characteristics and prognostic factors of adult hemophagocytic syndrome patients: a retrospective study of increasing awareness of a disease from a single-center in China. Orphanet J Rare Dis. $2015 ; 10: 20$.

4. Janka GE, Lehmberg K. Hemophagocytic syndromes - an update. Blood Rev. 2014; 28:135-142.

5. Arico M, Danesino C, Pende D, Moretta L. Pathogenesis of haemophagocytic lymphohistiocytosis. Br J Haematol. 2001; 114:761-69.

6. Henter JI, Elinder G, Soder O, Ost A. Incidence in Sweden and clinical features of familial hemophagocytic lymphohistiocytosis. Acta Paediatr Scand. 1991; 80: 428-435.

7. Niece JA, Rogers ZR, Ahmad N, Langevin AM, McClain KL. Hemophagocytic lymphohistiocytosis in Texas: observations on ethnicity and race. Pediatr Blood Cancer. 2010; 54:424-28.

8. Machaczka M, Vaktnas J, Klimkowska M, Hagglund H. Malignancy-associated hemophagocytic lymphohistiocytosis in adults: a retrospective populationbased analysis from a single center. Leuk Lymphoma. 2011; 52:613-619.

9. Ramos-Casals M, Brito-Zerón P, López-Guillermo A, Khamashta MA, Bosch X. Adult haemophagocytic syndrome. Lancet. 2014; 383:1503-1516.

10. Veerakul G, Sanpakit K, Tanphaichitr VS, Mahasandana C, Jirarattanasopa N. Secondary hemophagocytic lymphohistiocytosis in children: an analysis of etiology and outcome. J Med Assoc Thai. 2002; 85:S530-541.

11. Willemze R, Jansen PM, Cerroni L, Berti E, Santucci M, Assaf C, Canninga-van Dijk MR, Carlotti A, Geerts ML,
Hahtola S, Hummel M, Jeskanen L, Kempf W, et al, and EORTC Cutaneous Lymphoma Group. Subcutaneous panniculitis-like T-cell lymphoma: definition, classification, and prognostic factors: an EORTC Cutaneous Lymphoma Group Study of 83 cases. Blood. 2008; 111:838-845.

12. Kelly C, Salvi S, McClain K, Hayani A. Hemophagocytic lymphohistiocytosis associated with precursor B acute lymphoblastic leukemia. Pediatr Blood Cancer. 2011; 56:658-660.

13. Hagihara M, Inoue M, Hua J, Iwaki Y. Lymphocytedepleted Hodgkin lymphoma complicating hemophagocytic lymphohistiocytosis as an initial manifestation: a case report and review of the literature. Intern Med. 2012; 51: 3067-3072.

14. Celkan T, Berrak S, Kazanci E, Ozyürek E, Unal S, Uçar C, Yilmaz S, Gürgey A. Malignancy-associated hemophagocytic lymphohistiocytosis in pediatric cases: a multicenter study from Turkey. Turk J Pediatr. 2009; 51:207-213.

15. Kimura H, Ito $\mathrm{Y}$, Kawabe $\mathrm{S}$, Gotoh $\mathrm{K}$, Takahashi $\mathrm{Y}$, Kojima S, Naoe T, Esaki S, Kikuta A, Sawada A, Kawa K, Ohshima K, Nakamura S. EBV-associated T/NK-cell lymphoproliferative diseases in nonimmunocompromised hosts: prospective analysis of 108 cases. Blood. 2012; 119:673-686.

16. Aronson IK, Worobec SM. Cytophagic histiocytic panniculitis and hemophagocytic lymphohistiocytosis: an overview. Dermatol Ther (Heidelb). 2010; 23:389-402.

17. Otrock ZK, Eby CS. Clinical characteristics, prognostic factors, and outcomes of adult patients with hemophagocytic lymphohistiocytosis. Am J Hematol. 2015; 90:220-224.

18. Murphy EP, Mo J, Yoon JM. Secondary Hemophagocytic Lymphohistiocytosis in a Patient With Favorable Histology Wilms Tumor. J Pediatr Hematol Oncol. 2015; 37:e494-496.

19. Usmani GN, Woda BA, Newburger PE. Advances in understanding the pathogenesis of HLH. Br J Haematol. 2013; 161:609-622.

20. Kounami S, Nakayama K, Yoshiyama M, Rikoh M, Watanabe T, Takifuji K, Yoshikawa N. Early-onset hemophagocytic lymphohistiocytosis after the start of chemotherapy for advanced neuroblastoma. Pediatr Hematol Oncol. 2012; 29:99-103.

21. Ishii E, Ohga S, Imashuku S, Yasukawa M, Tsuda H, Miura I, Yamamoto K, Horiuchi H, Takada K, Ohshima K, Nakamura S, Kinukawa N, Oshimi K, Kawa K. Nationwide survey of hemophagocytic lymphohistiocytosis in Japan. Int J Hematol. 2007; 86:58-65.

22. Yu JT, Wang CY, Yang Y, Wang RC, Chang KH, Hwang WL, Teng CL. Lymphoma-associated hemophagocytic lymphohistiocytosis: experience in adults from a single institution. Ann Hematol. 2013; 92:1529-1536.

23. Han AR, Lee HR, Park BB, Hwang IG, Park S, Lee SC, Kim K, Lim HY, Ko YH, Kim SH, Kim WS. Lymphomaassociated hemophagocytic syndrome: clinical features and treatment outcome. Ann Hematol. 2007; 86:493-498. 
24. Li F, Li P, Zhang R, Yang G, Ji D, Huang X, Xu Q, Wei Y, Rao J, Huang R, Chen G. Identification of clinical features of lymphoma-associated hemophagocytic syndrome (LAHS): an analysis of 69 patients with hemophagocytic syndrome from a single-center in central region of China. Med Oncol. 2014; 31:902.

25. $\mathrm{Xu} \mathrm{Z}$, Burns BF. Hemophagocytosis due to bone marrow ALCL, ALK-. Blood. 2014; 124:478.

26. Shah M, Karnik L, Nadal-Melsió E, Reid A, Ahmad R, Bain BJ. ALK positive anaplastic large cell lymphoma presenting with hemophagocytic lymphohistiocytosis. Am J Hematol. 2015; 90:746.

27. Matsumura Y, Kuroda J, Shimura Y, Kiyota M, YamamotoSugitani M, Kobayashi T, Matsumoto Y, Horiike S, Taniwaki M. Cyclosporine A and reduced-intensity conditioning allogeneic stem cell transplantation for relapsed angioimmunoblastic T cell lymphoma with hemophagocytic syndrome. Intern Med. 2012; 51:2785-2787.

28. Glaudemans AW, Slart RH, Pruim J. Panniculitis-like T-cell lymphoma detected by positron emission tomography/ computed tomography scanning in a patient with haemophagocytic syndrome. Eur J Haematol. 2011; 87:379.

29. Ayala E, Chalhoub J, Kharfan-Dabaja MA. Umbilical cord blood transplantation induces a durable remission in hepatosplenic gamma-delta $\mathrm{T}$ cell lymphoma with associated hemophagocytic lymphohistiocytosis. Am J Hematol. 2014; 89:934-935.

30. Kim J, Yoo SW, Kang SR, Bom HS, Song HC, Min JJ. Clinical implication of F-18 FDG PET/CT in patients with secondary hemophagocytic lymphohistiocytosis. Ann Hematol. 2014; 93:661-667.

31. Rodríguez I, Grau J, Sancho JM, Ribera JM. [Diffuse large B cell lymphoma associated with hemophagocytic syndrome]. [Article in Spanish]. Med Clin (Barc). 2011; 136:87-88.

32. Devitt K, Cerny J, Switzer B, Ramanathan M, Nath R, Yu H, Woda BA, Chen BJ. Hemophagocytic lymphohistiocytosis secondary to T-cell/histiocyte-rich large B-cell lymphoma. Leuk Res Rep. 2014; 3:42-4.

33. Alaoua A, Gilbert G, Ghannouchi N, Houchlef M, Letaief A, Bahri F. Primary bilateral adrenal lymphoma revealed by hemophagocytic syndrome. Ann Endocrinol (Paris). 2011; 72:247-250.

34. Moritake $H$, Kamimura $S$, Nunoi $H$, Nakayama $H$, Suminoe A, Inada H, Inagaki J, Yanai F, Okamoto Y, Shinkoda Y, Shimomura M, Itonaga N, Hotta N, et al. Clinical characteristics and genetic analysis of childhood acute lymphoblastic leukemia with hemophagocytic lymphohistiocytosis: a Japanese retrospective study by the Kyushu-Yamaguchi Children's Cancer Study Group. Int J Hematol. 2014; 100:70-78.

35. Trebo MM,AttarbaschiA, Mann G, Minkov M, KornmüllerR, Gadner H. Histiocytosis following T-acute lymphoblastic leukemia: a BFM study. Leuk Lymphoma. 2005; 46: $1735-1741$.
36. Takahashi T, Matsugama M. Refractory hemophagocytic syndrome in a patient with acute myelocytic leukemia. Blood. 2013; 121:2820.

37. Lackner H, Seidel MG, Strenger V, Sovinz P, Schwinger W, Benesch M, Sperl D, Urban C. Hemophagocytic syndrome in children with acute monoblastic leukemia-another cause of fever of unknown origin. Support Care Cancer. 2013; 21:3519-3523.

38. Yamazaki S, Nakamura F, Nasu R, Nannya Y, Ichikawa M, Kurokawa M. Haemophagocytic lymphohistiocytosis is a recurrent and specific complication of acute erythroid leukaemia. Br J Haematol. 2011; 153:669-672.

39. Akyay A. Hemophagocytosis in acute megakaryocytic leukemia: hemophagocytosis or emperipolesis? J Pediatr Hematol Oncol. 2013; 35:578.

40. Kamangar E, Zhao W. Hemophagocytosis in a patient with persistent chronic lymphocytic leukemia. Blood. 2013; 122:2149.

41. Rivière S, Galicier L, Coppo P, Marzac C, Aumont C, Lambotte O, Fardet L. Reactive hemophagocytic syndrome in adults: a retrospective analysis of 162 patients. Am J Med. 2014; 127:1118-1125.

42. Tsuji T, Yamasaki H, Arima N, Tsuda H. Hemophagocytic lymphohistiocytosis associated with myelodysplastic syndromes. Int J Hematol. 2010; 92:547-549.

43. Tothova Z, Berliner N. Hemophagocytic Syndrome and Critical Illness: New Insights into Diagnosis and Management. J Intensive Care Med. 2015; 30:401-412.

44. Aryal MR, Badal M, Giri S, Aryal S. Haemophagocytic lymphohistiocytosis mimicking septic shock after the initiation of chemotherapy forsquamous cell carcinoma of the neck. BMJ Case Rep. 2013; 2013.

45. Chaudary IU, Bojal SA, Attia A, Al-Dossary B, Al Dayel A, Amr SS. Mediastinal endodermal sinus tumor associated with fatal hemophagocytic syndrome. Hematol Oncol Stem Cell Ther. 2011; 4:138-141.

46. Delavigne K, Bérard E, Bertoli S, Corre J, Duchayne E, Demur C, Mansat-De Mas V, Borel C, Picard M, Alvarez M, Sarry A, Huguet F, Récher C. Hemophagocytic syndrome in patients with acute myeloid leukemia undergoing intensive chemotherapy. Haematologica. 2013; 99: 474-480.

47. Higuchi $\mathrm{T}$, Yamazoe $\mathrm{M}$, Yamaguchi $\mathrm{N}$, Okada $\mathrm{S}$. Hemophagocytic lymphohistiocytosis following differentiation syndrome in acute promyelocytic leukemia. Leuk Lymphoma. 2011; 52:1601-1603.

48. Tiong IS, Lau MB, Toumoua S, Chiruka S. A case of hemophagocytic lymphohistiocytosis in a patient with chronic lymphocytic leukemia after treatment with fludarabine, cyclophosphamide, and rituximab chemotherapy, with autopsy findings. Case Rep Hematol. 2012; 2012:326053.

49. Lehmberg K, Sprekels B, Nichols KE, Woessmann W, Müller I, Suttorp M, Bernig T, Beutel K, Bode SF, 
Kentouche K, Kolb R, Längler A, Minkov M, et al. Malignancy- associated haemophagocytic lymphohistiocytosis in children and adolescents. $\mathrm{Br} \mathrm{J}$ Haematol. 2015; 70:539-549.

50. Machaczka M, Klimkowska M, Chiang SC, Meeths M, Muller ML, Gustafsson B, Henter JI, Bryceson YT. Development of classical Hodgkin's lymphoma in an adult with biallelic STXBP2 mutations. Haematologica. 2013; 98:760-764.

51. Booth C, Gilmour KC, Veys P, Gennery AR, Slatter MA, Chapel H, Heath PT, Steward CG, Smith O, O'Meara A, Kerrigan H, Mahlaoui N, Cavazzana-Calvo M, et al. $\mathrm{X}$-linked lymphoproliferative disease due to SAP/SH2D1A deficiency: a multicenter study on the manifestations, management and outcome of the disease. Blood. 2011; 117:53-62.

52. Lehmberg K, Ehl S. Diagnostic evaluation of patients with suspected haemophagocytic lymphohistiocytosis. Br J Haematol. 2013; 160:275-287.

53. Henter JI, Horne A, Arico M, Egeler RM, Filipovich AH, Imashuku S, Ladisch S, McClain K, Webb D, Winiarski J, Janka G. HLH-2004: diagnostic and therapeutic guidelines for hemophagocytic lymphohistiocytosis. Pediatr Blood Cancer. 2007; 48:124-131.

54. Takahashi N, Chubachi A, Miura I, Nakamura S, Miura AB. [Lymphoma-associated hemophagocytic syndrome in Japan]. [Article in Japanese]. Rinsho Ketsueki. 1999; 40:542-549.

55. Maruoka H, Inoue D, Takiuchi Y, Nagano S, Arima H, Tabata S, Matsushita A, Ishikawa T, Oita T, Takahashi T. IP-10/CXCL10 and MIG/CXCL9 as novel markers for the diagnosis of lymphoma-associated hemophagocytic syndrome. Ann Hematol. 2014; 93:393-401.

56. Lehmberg K, Nichols KE, Henter JI, Girschikofsky M, Greenwood T, Jordan M, Kumar A, Minkov M, La Rosée P, Weitzman S, Study Group on Hemophagocytic Lymphohistiocytosis Subtypes of the Histiocyte Society. Consensus recommendations for the diagnosis and management of hemophagocytic lymphohistiocytosis associated with malignancies. Haematologica. 2015; 100:997-1004.

57. Menard F, Besson C, Rince $\mathrm{P}$, Lambotte O, Lazure $\mathrm{T}$, Canioni D, Hermine O, Brousset P, Martin A, Gaulard P, Raphaël M, Larroche C. Hodgkin lymphoma-associated hemophagocytic syndrome: a disorder strongly correlated with Epstein-Barr virus. Clin Infect Dis. 2008; 47:531-534.

58. Fardet L, Lambotte O, Meynard JL, Kamouh W, Galicier L, Marzac C, de Labarthe A, Cabane J, Lebbe C, Coppo P, Molina JM, Martinez V. Reactive haemophagocytic syndrome in $58 \mathrm{HIV}-1$-infected patients: clinical features, underlying diseases and prognosis. AIDS. 2010; 24: 1299-1306.

59. Tsuji T, Hirano T, Yamasaki H, Tsuji M, Tsuda H. A high sIL-2R/ferritin ratio is a useful marker for the diagnosis of lymphoma-associated hemophagocytic syndrome. Ann Hematol. 2014; 93:821-826.
60. Allen CE, Yu X, Kozinetz CA, McClain KL. Highly elevated ferritin levels and the diagnosis of hemophagocytic lymphohistiocytosis. Pediatr Blood Cancer. 2008; 50:1227-35.

61. Schram AM, Berliner N. How I treat hemophagocytic lymphohistiocytosis in the adult patient. Blood. 2015; 125:2908-2914.

62. Johnson TS, Terrell CE, Millen SH, Katz JD, Hildeman DA, Jordan MB. Etoposide selectively ablates activated T cells to control the immunoregulatory disorder hemophagocytic lymphohistiocytosis. J Immunol. 2014; 192:84-91.

63. Imashuku S, Kuriyama K, Teramura T, Ishii E, Kinugawa N, Kato M, Sako M, Hibi S. Requirement for etoposide in the treatment of Epstein-Barr virus-associated hemophagocytic lymphohistiocytosis. J Clin Oncol. 2001; 19:2665-2673.

64. Chellapandian D, Das R, Zelley K, Wiener SJ, Zhao H, Teachey DT, Nichols KE, EBV-HLH Rituximab Study Group. Treatment of Epstein Barr virus-induced haemophagocytic lymphohistiocytosis with rituximabcontaining chemo-immunotherapeutic regimens. $\mathrm{Br} \mathrm{J}$ Haematol. 2013; 162:376-382.

65. Jordan MB, Allen CE, Weitzman S, Filipovich AH, McClain KL. How I treat hemophagocytic lymphohistiocytosis. Blood. 2011; 118:4041-4052.

66. Wang Y, Huang W, Hu L, Cen X, Li L, Wang J, Shen J, Wei N, Wang Z. Multi-center study of combination DEP regimen as a salvage therapy for adult refractory hemophagocytic lymphohistiocytosis. Blood. 2015; 126:186-92.

67. Balamuth NJ, Nichols KE, Paessler M, Teachey DT. Use of rituximab in conjunction with immunosuppressive chemotherapy as a novel therapy for Epstein Barr virusassociated hemophagocytic lymphohistiocytosis. J Pediatr Hematol Oncol. 2007; 29:569-573.

68. Larroche C. Hemophagocytic lymphohistiocytosis in adults: diagnosis and treatment. Joint Bone Spine. 2012; 79:356-61.

69. Foggo V, Cavenagh J. Malignant causes of fever of unknown origin. Clin Med (Lond). 2015; 15:292-294.

70. Dalal BI, Vakil AP, Khare NS, Wang SY, Richards MJ, Chen LY. Abnormalities of the lymphocyte subsets and their immunophenotype, and their prognostic significance in adult patients with hemophagocytic lymphohistiocytosis. Ann Hematol. 2015; 94:1111-1117.

71. Emmenegger U, Schaer DJ, Larroche C, Neftel KA. Haemophagocytic syndromes in adults: current concepts and challenges ahead. Swiss Med Wkly. 2005; 135: 299-314.

72. Yang YQ, Ding CY, Xu J, Fan L, Wang L, Tian T, Li TN, $\mathrm{Li}$ JY, Xu W. Exploring the role of bone marrow increased FDG uptake on PET/CT in patients with lymphomaassociated hemophagocytic lymphohistiocytosis: a reflection of bone marrow involvement or cytokine storm? Leuk Lymphoma. 2015; 19:1-8. 